\title{
História e Filosofia da Ciência na Licenciatura em Fí- sica, uma proposta de ensino através da pedagogia de projetos $^{+*}$
}

Washington Luiz Raposo

Centro Federal de Educação Tecnológica Celso Suckow da Fonseca Nova Friburgo - RJ

\section{Resumo}

Neste artigo, apresentamos uma proposta de ensino baseada na Pedagogia de Projetos levada a termo durante o ano de 2013 em uma das atividades de extensão realizadas com alunos do curso de licenciatura em Física do CEFET/RJ - UnED Nova Friburgo. Nessa atividade buscamos uma abordagem didática onde o aluno assumisse o papel de protagonista no próprio processo de aprendizagem e de colaborador no aprendizado de seus colegas de curso e de alunos de nível médio de uma escola pública parceira no projeto. $O$ objetivo central foi tornar mais efetiva à aprendizagem de História e Filosofia da Ciência (HFC) e Natureza da Ciência $(N D C)$ por estes licenciandos e pelos alunos da escola parceira.

Palavras-chave: História e Filosofia da Ciência. Formação de Professores. Licenciatura em Física. Pedagogia de Projetos.

\begin{abstract}
In this paper, we present a teaching proposal centered on the Projects Pedagogy brought to completion in the year 2013 with
\end{abstract}

\footnotetext{
History and Science Philosophy in Physics Degree, a teaching proposal through the Projects Pedagogy

* Recebido: março de 2014.

Aceito: abril de 2014.
} 
students of Physics Teachers' Degree of the CEFET/RJ - in the Nova Friburgo Unity. In this activity, we searched for putting these students as protagonists of their own learning process and as collaborators of others classmates in a Public High School partner of the project. The central objective of this work was to enlarge the learning of History and Philosophy of Science and Nature of Science for these students and of the students of the High School partner in this project.

Keywords: History and Philosophy of Science. Teachers' Education. Physics Teaching. Projects Pedagogy.

\section{Introdução}

Nossa proposta para este artigo é de socializar as atividades desenvolvidas no projeto de extensão denominado Oficina de Experimentos Históricos uma Proposta de Contextualização da Física, levado a termo durante o ano de 2013 por alunos do curso de licenciatura em Física do CEFET-RJ/UnED Nova Friburgo.

Nessa atividade de extensão ${ }^{1}$ buscamos uma maneira de potencializar a aprendizagem e o entendimento dos alunos sobre temas de Natureza da Ciência (NDC) e de História e Filosofia da Ciência (HFC), de evidenciar a importância e utilidade destes temas para o ensino de Física, além de propiciar experiências práticas de sua utilização.

Conforme nos mostra Martins A. (2007), são inúmeras as dificuldades encontradas pelos professores na aplicação de HFC no ensino regular que inibem a sua utilização em sala da aula. Mesmo os professores que tiveram amplo contato com estudos dessa natureza, por diversos fatores, não aplicam em sua prática pedagógica tais conhecimentos, ainda que os considerem importantes (MARTINS A., 2007; 2012). Ainda em Martins A. (2007) encontramos diversas justificativas práticas para a não utilização de HFC em sala de aula como: a falta de material didático apropriado, ou má qualidade do conteúdo apresentado (FORATO et al., 2009), os conteúdos curriculares inchados a que estes professores estão presos, os pro-

${ }^{1}$ Para não causar confusão na compreensão do texto, vamos adotar neste artigo o termo atividade de extensão como referência a todo o "projeto de extensão" que realizamos durante o ano citado e utilizar o termo projeto de forma mais geral, nos referindo a qualquer projeto, ou como referência à metodologia didática da "Pedagogia de Projetos". 
blemas de formação dos professores, as dificuldades didáticas na aplicação destes assuntos e outros.

Se a HFC é, quase, uma unanimidade, porque não a vemos contemplada nas salas de aula do ensino médio e em livros didáticos? A resposta é, certamente, simples: não é fácil fazer. [...] Do ponto de vista da formação de professores, não basta que tenhamos disciplinas de HFC nas licenciaturas. É preciso refletir sobre o como fazer (MARTINS A., 2007, p. 127).

Pensando nessa problemática, optamos por adotar uma postura diferenciada da tradicionalmente utilizada em disciplinas de HFC e NDC. Adotamos a abordagem metodológica da Pedagogia de Projetos (HERNÁNDEZ, 1998; 2008; MARTINS J. S., 2005; 2007; PRADO, 2003) e o incentivo à autonomia destes licenciandos em todas as etapas, desde a pesquisa e os debates até a elaboração de um produto final de aprendizado.

Propomos como produto final (e "problema" motivador) a construção de um minicurso de HFC, com discussões de NDC, que deveria ser elaborado e apresentado pelos próprios licenciandos envolvidos. Sua apresentação seria de duas formas: $1^{\circ}$ ) para alunos do Ensino Médio - em quatro encontros ou aulas; $2^{\circ}$ ) para os alunos da licenciatura em física, colegas de graduação - em três encontros durante a semana de extensão ${ }^{2}$ do CEFET-RJ. Para tanto buscamos a parceria de uma escola pública estadual, na qual foi possível contar com a participação de duas turmas do $1^{\circ}$ ano do Ensino Médio, as quais as aulas do minicurso foram ministradas.

Objetivamos, com essa abordagem, incentivar o protagonismo (FERRETTI et al., 2004; FERRARI, 2008) destes licenciando no seu próprio processo de aprendizagem, estimular a pesquisa, esclarecê-los quanto aos critérios de seleção de textos confiáveis sobre o tema e possibilitar a prática pedagógica de HFC e NDC, discutindo e repensando suas possibilidades de utilização no ensino de Física.

\footnotetext{
2 A quantidade de encontros para a apresentação do minicurso foi determinada em função do tempo disponibilizado pelo professor da escola parceira, dentro de seu próprio horário de aula, e dos três dias disponíveis para o mesmo na semana de extensão.
} 


\section{Pedagogia de Projetos}

A metodologia de ensino por projetos foi proposta inicialmente por John Dewey (1859-1952), filósofo norte-americano que influenciou educadores de várias partes do mundo com suas ideias a favor do conceito de escola ativa, na qual o aluno deveria ter iniciativa, originalidade e agir de forma cooperativa. No Brasil, ele inspirou o movimento conhecido como Escola Nova, liderado por Anísio Teixeira, no qual a atividade prática e a democracia eram importantes ingredientes do processo educacional (FERRARI, 2008).

A pedagogia de Dewey apresentava muitos aspectos inovadores, distinguindo-se especialmente pela oposição à escola tradicional e a visão de que a educação tem como finalidade propiciar aos alunos condições para que resolvam por si próprios seus problemas (VIEIRA, 2010). Esta é uma visão pragmática da educação que se baseia na própria filosofia por ele defendida. A partir de Dewey que o termo projeto começa a ser utilizado amplamente entre professores americanos, sendo visto como método de educação progressista baseada na participação ativa dos alunos em todo o processo educacional (FERRARI, 2008).

Um projeto, em geral, tem como etapas: a definição dos objetivos, planejamento, investigação, execução, replanejamento, apresentação de resultados e avaliação. Na Pedagogia de Projetos, parte-se de um tema gerador, um problema a ser resolvido, que deve dar significado a todo o estudo posterior. Incorporando à Pedagogia de Projetos às ideias freireanas, teremos este tema gerador sendo extraído da problematização da vida prática dos educandos. Por meio desta problematização o aluno deve construir e reconstruir o conhecimento de sua realidade para nela intervir, uma vez que passa a compreendê-la melhor (FREIRE, 1987).

Na Pedagogia de Projetos, o objetivo principal é fazer com que o aluno participe efetivamente de todo o processo de construção de conhecimento, tirandoo do lugar de passividade e colocando-o no centro do processo educacional. Desse modo, após a escolha do tema, o professor deverá delinear as etapas do projeto, porém estas não devem ser rígidas, fechadas, e sim flexíveis e adaptativas, modificando-se conforme as necessidades e prioridades que surgirem no seu desenrolar (Nogueira, 2002).

Segundo Hernández (2008), não há um método fixo e sim uma série de condições a serem respeitadas. E mais, "Todas as coisas podem ser ensinadas por meio de projetos, basta que se tenha uma dúvida inicial e que se comece a pesquisar e buscar evidências sobre o assunto" (Hernández, 2008). O importante é que o aluno perceba a relevância do estudo, associado à valorização do seu eu e das necessidades de crescimentos e desenvolvimento pessoal. 
A Pedagogia de Projetos exige do professor uma postura diferenciada, a de orientador e mediador da aprendizagem e, não mais, a postura de detentor do conhecimento e principal agente do processo educacional. Nela as atividades educativas são criadas e planejadas com uma finalidade bem determinada e com duração temporal bem definida. Uma vez atingidos os objetivos, ou esgotadas as possibilidades, o mesmo é finalizado e outro projeto, com objetivos distintos ou desdobramentos do primeiro, pode ser iniciado.

$\mathrm{Na}$ educação superior, o ensino por meio do desenvolvimento de projetos pode ser uma forma de promover a interação entre todos os sujeitos envolvidos no processo de ensino-aprendizagem, propiciar o desenvolvimento da autonomia do aluno e a construção de conhecimentos de distintas áreas do saber, por meio da busca de conhecimentos significativos para a compreensão, representação e resolução de uma situação-problema (VIEIRA, 2010).

\section{Protagonismo Juvenil na Educação}

O protagonismo dos alunos é um conceito que aparece com diferentes interpretações na literatura especializada e está, muitas vezes, vinculado a outros conceitos como "participação", "responsabilidade social", "identidade", "autonomia" e "cidadania" (FERRETTI et al., 2004). Parece consensual entre os autores que a "preparação para a cidadania" é o principal agregador de significados a estes termos, porém, segundo Ferretti et al (2004), se buscarmos a etimologia do termo "protagonismo" (protagnistés), perceberemos que ele designava o ator principal do teatro grego, ou aquele que ocupava o lugar principal em um acontecimento.

$\mathrm{O}$ discurso da ativa participação dos alunos no próprio processo de aprendizagem nos remete aos anos 20 e 30 do século passado, quando o pensamento de John Dewey foi adotado por diversos teóricos da educação, conforme já mencionado. Dewey defendia que o processo educacional deve ser baseado nos interesses e na experiência dos alunos, com igual valorização da criatividade e das habilidades técnicas.

Em detrimento às diferentes abordagens do termo, optamos por adotar o significado mais próximo de sua etimologia, ou seja, de protagonista como sendo o ator principal do processo educacional. Nesse sentido, o aluno assume, ele próprio, a responsabilidade pela construção de seu conhecimento. Ele próprio é "fonte de iniciativa (ação), liberdade (opção) e compromisso (responsabilidade)" (COSTA, 2001). Dessa forma, o aluno passa a ocupar o centro do processo educativo e o trabalho do professor deverá ser de orientar a construção de conhecimentos e valores. Não nos furtamos ao aspecto sócio-educacional ao qual o termo está geralmen- 
te vinculado, mas nos apoiamos principalmente à ideia de autonomia, iniciativa $\mathrm{e}$ envolvimento pessoal do aluno no trabalho a ser desenvolvido. Como veremos mais adiante, os estudos de HFC e NDC podem se mostrar, também, muito úteis aos propósitos de formação social e cultural dos estudantes.

\section{Importância da HFC e NDC no ensino de Física}

Dentre as diversas propostas de abordagem para o ensino das ciências ${ }^{3}$, a vertente que apoia o uso de HFC no ensino de física vem sendo amplamente defendida no exterior desde a década de 60 , com o desenvolvimento do projeto de física de Harvard ${ }^{4}$, e no Brasil a partir da década de 80, logo após a tradução do mesmo para o nosso idioma, em Portugal (PEDUZZI et al., 1990).

$\mathrm{Na}$ defesa da abordagem de HFC no ensino de física, contamos com trabalhos que apresentam diversos benefícios da inserção da HFC como estratégia didática (LEDERMAN, 2007) ou mesmo como conteúdo importante de ser abordado nos diferentes cursos das ciências. Citando apenas algumas contribuições nesse sentido temos: Whitaker (1979), Zanetic (1989), Matthews (1994), Gil-Pérez et al. (2001), Peduzzi (2001), Holton (2003), El-Hani (2006), Lederman (2007), Martins, A. (2007; 2012), Forato (2008; 2009A; 2011).

A abordagem histórico-filosófica da Ciência para o ensino de física, se bem estruturada e coerente, pode propiciar o aprendizado significativo de equações e conceitos; ser útil para lidar com a problemática das concepções alternativas; incrementar a cultura geral dos alunos; desmistificar o método científico; chamar a

3 Abordagem CTS, abordagem construtivista, ensino por investigação, o enfoque contextual, abordagem problematizadora e outras.

4

Projeto educacional desenvolvido pela National Science Foundation com a universidade de Harvard e implementado nos EUA entre os anos de 1962 e 1970, cujo nome original é Project Physics Course. Fundamentado em princípios históricos, com forte componente humanístico e preocupado com as dimensões cultural e filosófica da ciência, contou com a participação de historiadores e filósofos da ciência, físicos, astrônomos, químicos, educadores de ciências, psicólogos, especialistas de avaliação, dentre outros profissionais. Seu sucesso em evitar a evasão dos estudantes, atrair mulheres para os cursos de ciências, desenvolver a habilidade do raciocínio crítico e elevar a média de acertos alcançada em avaliações, forneceu evidencias suficientes para os que, hoje, advogam a favor da história, filosofia e sociologia da ciência. (MATTHEWS, 1995; FREIRE JR.; CARVALHO; SERPA, 2000; SAUERWEIN; DELIZOICOV, 2008). O Projeto Harvard, que tinha sido idealizado para o ensino médio, foi também adotado nos cursos introdutórios nas faculdades e foi muito bem até o começo dos anos 70, como a suspensão do financiamento dos cursos de preparação dos professores pelo governo Nixon (OLIVEIRA; FREIRE JR, 2006). 
atenção para a ideia da metafísica e tornar as aulas de Física mais desafiadoras e interessantes (PEDUZZI, 2001).

O ensino tradicional, "doutrinário", que ainda representa a metodologia mais utilizada em disciplinas específicas de física, dá origem à concepção "deformada" de ciência que os licenciandos dessas áreas apresentam (FERNANDEZ, 2000). Uma ciência de verdades absolutas, feita por grandes gênios repentinos e de inesperadas descobertas espetaculares. Esse tipo de ensino ignora também o papel da criatividade e da imaginação na produção científica, além de apresentarem uma falta de compreensão das noções de 'fato', 'evidencia', 'observação', 'experimentação', 'modelos', 'leis' e 'teorias' e a inter-relação entre eles (EL-HANI, 2006).

Para os futuros professores, o estudo de HFC e de NDC, além de aumentar em muito sua compreensão da Ciência, pode mostrar como a sociedade, o contexto histórico e os interesses econômicos e políticos podem influenciar no trabalho da Ciência. Possibilita-se, assim, a construção de aulas mais contextualizadas e significativas.

A importância desses estudos no âmbito da formação de professores das áreas da ciência já vem sendo salientada há algum tempo por Sandoval e Cudmani (1993), Matthews (1995), Harres (1999), Gil-Pérez et al. (2001), El-Hani (2006), Martins, R. (2006), Moreira et al. (2007) entre outros. Porém, devido às implicações teóricas e práticas envolvidas e necessárias a boa utilização da HFC para o ensino (FORATO, 2006), fica evidente que para termos bons professores de ensino básico, preparados para tal abordagem, tornam-se imprescindível que os mesmos tenham contato com as dimensões histórico-filosóficas em sua formação e, além disso, que recebam orientação de como utilizar a HFC para o ensino de física (MARTINS A., 2007). De fato, os professores atuais não estão bem preparados para lidar com as versões problemáticas da história da ciência e com as inúmeras controvérsias presentes no desenvolvimento científico (GIL-PÉREZ et al., 2001; FERNÁNDEZ, 2000; LEDERMAN, 1992, 2007).

É nesse sentido que discutimos a proposta de ensino de HFC e NDC, na licenciatura em física, através da Pedagogia de Projetos, da problematização de situações educacionais e do protagonismo dos estudantes no processo de pesquisa e aprendizagem conforme discutiremos a seguir.

\section{HFC e NDC na licenciatura em física através da Pedagogia de Pro- jetos}

Nossa proposta de discutir temas de Natureza da Ciência (NDC) e de História e Filosofia da Ciência (HFC) na licenciatura em física não é nenhuma novi- 
dade ou pioneirismo. Em verdade, muitas propostas, relatos de experiências e estudos sobre a inserção de discussões desse teor na graduação em física têm sido publicados em revistas e discutido em congressos há bastante tempo. O que trazemos nesse artigo é mais uma experiência levada a cabo e que os resultados obtidos nos motivaram a tornar pública tal atividade realizada.

Para a realização desta atividade, escolhemos um recorte histórico em particular, como tema gerador das questões de NDC e questões histórico-filosóficas que permeiam o processo de elaboração da Ciência. Escolhemos estudar os experimentos, as invenções, a vida e obra de Galileu Galilei, motivados principalmente pela importância do momento histórico e do personagem Galileu para a chamada Ciência Moderna. No entanto, o fato de percebermos uma forte aceitação do tema por parte dos participantes, nos motivou a prosseguir com o mesmo, sem a necessidade de analisarmos outras propostas de temas que poderiam surgir.

A atividade foi realizada no decorrer de oito meses (de março a outubro), com encontros semanais de quatro horas/aula. Dividimos o mesmo em quatro etapas de trabalho de dois meses, em média. Reservamo-nos o direito de alguma flutuação das três etapas iniciais, só passando para a próxima etapa ao percebermos que os conhecimentos discutidos foram assimilados.

$\mathrm{Na}$ primeira etapa foram apresentados textos introdutórios sobre a vida e obra de Galileu e propostos vídeos sobre o mesmo tema, para começar a "ambientar" estes alunos aos estudos de HFC, conforme podemos conferir na Tabela 1. Discutimos, também nessa etapa, as lendas e verdades sobre a sua vida e obra (MARTINS R., 2010) e realizamos um levantamento sobre suas invenções e teorias.

$\mathrm{Na}$ segunda etapa foram discutidos os aspectos filosóficos do trabalho de Galileu e analisados os diferentes pontos de vista a respeito do seu trabalho. Nessa etapa estudamos alguns textos de Alexandre Koyré, Stillmann Drake, e Bernard Cohen e discutimos a visão empirista de Galileu, defendida por Drake, confrontando-a com o ponto de vista racionalista, platônico, defendido por Koyré. Analisamos ainda os relatos e justificativas desses historiadores a respeito da realização física ou não das experiências descritas por Galileu em seus livros e a mudança epistemológica provocada por seu trabalho. Os textos utilizados nesta etapa também estão listados na Tabela 1, bem como os das demais etapas.

$\mathrm{Na}$ terceira etapa, estudamos trechos dos textos originais de Galileu de modo a extrair informações sobre os experimentos por ele elaborados, reais ou de pensamento (ZYLBERSZTAJN, 1988), além de buscarmos compreender sua maneira de demonstrar geometricamente teoremas e ideias. Nessa etapa, dedicamonos, também a montagem do experimento do plano inclinado, respeitando as me- 
didas e os detalhes descritos em "Duas Novas Ciências" (GALILEI, 1988) e a análise lógico-geométrica dos teoremas que estão relacionados a este experimento. Além disso, elaboramos uma montagem experimental para analisar a queda livre de esferas de diâmetros e materiais diversos com o intuito de discutirmos as conclusões de Galileu sobre a queda dos "graves". A descrição detalhada destes experimentos, a análise dos dados colhidos e suas discussões frente à obra de Galileu, foram reservadas para um próximo trabalho.

$\mathrm{Na}$ quarta e última etapa, elaboramos o minicurso sobre a vida e obra de Galileu, baseada principalmente nas discussões a cerca dos seus experimentos, suas invenções, suas descrições matemáticas, análise dos mitos e verdades sobre seu trabalho e as mudanças provocadas no modo de se fazer ciência, herança de sua metodologia de pesquisa.

Tabela 1 - Textos e vídeos utilizados nas pesquisas e estudos com os licenciandos.

\begin{tabular}{|c|c|c|}
\hline Etapas & $N^{0}$ texto & Referências dos Textos ${ }^{5}$ \\
\hline \multirow{7}{*}{$1^{\mathrm{a}}$} & $1^{\mathrm{o}}$ & BAPTISTA, J. P. e FERRACIOLI, L., 1999 \\
\hline & $2^{\circ}$ & PEDUZZI, L. O. Q., 1996. \\
\hline & $3^{\circ}$ & COHEN, I. Bernard., 1967. \\
\hline & $4^{\circ}$ & ARAUJO, WALTER D., 2008. \\
\hline & $5^{\circ}$ & MARTINS, R. A., 2010. \\
\hline & \multirow{2}{*}{ Vídeos } & Galileu Galilei: a Batalha pelo Céu. \\
\hline & & Galileu Galilei: o mensageiro das estrelas. \\
\hline \multirow{5}{*}{$2^{\mathrm{a}}$} & $6^{\circ}$ & ZYLBERSZTAJN, A., 2009. \\
\hline & $7^{\circ}$ & ARAUJO, WALTER D., 2008. \\
\hline & $8^{\circ}$ & KOYRÉ, A., 1991. \\
\hline & $9^{\circ}$ & COHEN, I. Bernard, 1967. \\
\hline & $10^{\circ}$ & DRAKE, Stillman, 1970. \\
\hline \multirow{2}{*}{$3^{\mathrm{a}}$} & $11^{\circ}$ & PIRES, Antônio ST., 2008. \\
\hline & $12^{\circ}$ & GALILEI, G., 2005. \\
\hline \multirow{2}{*}{$4^{a}$} & $13^{\circ}$ & ARAUJO, WALTER D., 2008. \\
\hline & $14^{\circ}$ & GALILEI, G. 2005. \\
\hline
\end{tabular}

5 As referências completas estão discriminadas no final deste trabalho em "referências de textos utilizados nas atividades de extensão". 


\section{O minicurso}

Este minicurso é o ponto mais importante de toda a atividade realizada. Nele reconhecemos a motivação, o problema a ser solucionado e o produto final de todo estudo realizado. Como problema a ser solucionado pelos licenciandos podemos atribuir uma questão motivadora importante: como ensinar estes temas em um minicurso para o ensino médio e para a graduação? O minicurso representou, ainda, o produto final de trabalho de onde pudemos avaliar todo aprendizado adquirido por eles e onde eles puderam exercitar práticas pedagógicas e expor aos demais colegas o fruto do trabalho realizado.

Este minicurso foi elaborado por eles, porém com o apoio e supervisão do orientador da atividade de extensão e teve como elementos importantes: um resumo da vida de Galileu; suas reais contribuições ao estudo de movimento; as demonstrações geométricas de seus teoremas; o aperfeiçoamento da luneta e sua utilização nas observações do Céu; a análise dos mitos quanto a sua fabricação e de seu pioneirismo nas observações da Lua e do Sol (MATINS, R., 2010); a realização dos experimentos, reais ou de pensamento (mentais); apresentação dos experimentos históricos do plano inclinado e da queda dos corpos, em formato de demonstração, discussão sobre as visões empirista e racionalista de sua obra; as suas contribuições para o método experimental e o nascimento da Ciência Moderna.

O minicurso foi apresentado, tanto para os alunos do ensino médio como para os alunos da graduação, durante a Semana Nacional de Ciência e Tecnologia (SNCT), que coincidiu com a Semana de Extensão do CEFET-RJ.

$\mathrm{Na}$ escola de nível médio os encontros foram de uma hora e meia cada (2 tempos de 45 minutos). O primeiro e segundo encontros ocorreram na própria SNCT, porém o mesmo foi finalizado na semana seguinte.

Os temas dos encontros estão na Tabela 2 e nela podemos perceber o foco principal de cada discussão.

No primeiro encontro, discutimos a física aristotélica devido à sua importância para compreender o trabalho e os embates científico-filosóficos da obra de Galileu.

No segundo encontro, os licenciandos se preocuparam em dar um panorama geral da vida e obra galileana para que os ouvintes pudessem se conscientizar do personagem histórica que foi Galileu e sua importância para a Ciência Moderna.

No terceiro encontro, foram discutidas as lendas e mitos a respeito de seu trabalho. Por exemplo, Thomas Harriot fez as primeiras observações da Lua e do Sol, através de uma luneta, meses antes de Galileu (MARTINS, 2010), no entanto todos aprendem que Galileu foi o primeiro a observar a Lua e as manchas solares 
com o uso de um instrumento óptico. E mais, algumas ideias a respeito do movimento já existiam desde a idade média. O teorema da velocidade média, por exemplo, já haviam sido desenvolvidos pelos estudiosos da escola de Merton, em Oxford, e tinha sido demonstrado matematicamente, de forma muito semelhante à utilizada por Galileu, por Nicole de Oresme, na França. No entanto, não era costume referendar trabalhos nessa época, então Galileu dá a entender que esta e outras ideias são realizações suas (MARTINS R., 2010).

O mais importante e difícil para estes licenciandos, nessa etapa, foi mostrar as falhas na descrição histórica sem diminuir a importância de Galileu e de sua obra para a Ciência Moderna.

Tabela 2 - Temas das aulas ministradas no minicurso na escola de nível médio parceira.

\begin{tabular}{|c|l|}
\hline $\begin{array}{c}\text { Encon- } \\
\text { tros }\end{array}$ & \multicolumn{1}{c|}{ Assunto } \\
\hline $1^{\circ}$ & A Física Aristotélica e sua influência na ciência medieval. \\
\hline $2^{\text {o }}$ & $\begin{array}{l}\text { Vida e obra de Galileu: vida, família, evolução acadêmica e fases do } \\
\text { seu trabalho (estudo da mecânica, luneta e observação do Céu, retor- } \\
\text { no aos estudos da mecânica), além dos motivos geradores dos seus } \\
\text { problemas com a inquisição. }\end{array}$ \\
\hline $3^{\text {o }}$ & $\begin{array}{l}\text { Os mitos e lendas a cerca do trabalho de Galileu: a invenção ou } \\
\text { aperfeiçoamento da luneta, a controvérsia sobre sua prioridade na } \\
\text { observação da Lua e das manchas solares, suas ideias a cerca do } \\
\text { estudo do movimento, discussão sobre a originalidade ou não de } \\
\text { alguns de seus teoremas. }\end{array}$ \\
\hline $4^{\text {o }}$ & $\begin{array}{l}\text { Apresentação dos experimentos do plano inclinado de Galileu e da } \\
\text { queda dos corpos, além da apresentação de suas análises e demons- } \\
\text { trações lógico-geométricas, conforme descritas no "Duas Novas } \\
\text { Ciências" (GALILEI, 1988) e discussão a respeito do ponto de vista } \\
\text { dos principais historiadores a respeito dos métodos utilizados por } \\
\text { Galileu em sua obra. }\end{array}$ \\
\hline
\end{tabular}

Ao encontro final, $4^{\circ}$ encontro, foi atribuído um caráter mais de demonstração experimental. Foram apresentadas as experiências do plano inclinado e da queda dos corpos, e discutidas as deduções geométricas e conclusões de Galileu a respeito destes estudos. Este último encontro representou um grande desafio para 
os licenciandos, uma vez que esses alunos da escola parceira, em particular, apresentam grandes dificuldades de compreensão da matemática e da geometria. Porém a geometria usada por Galileu é bastante básica e sua lógica não é tão complexa, se forem fornecidos subsídios para tal compreensão. No entanto, buscamos simplificar as demonstrações para facilitar a sua compreensão e utilizar diversos recursos para ajudá-los na compreensão desses estudos.

Concomitante com os dois primeiros encontros na escola de nível médio, ocorreram as apresentações do minicurso aos demais alunos de graduação na semana de extensão no CEFET-RJ/Nova Friburgo.

A versão do minicurso aplicada para os alunos de graduação foi bastante semelhante à apresentação no ensino médio, apenas a divisão de encontros foi de três dias, de duas horas e meia cada, e o rigor e profundidade das discussões foi mais acentuado. Outra importante diferença foi que aos alunos de nível médio viram as deduções de teoremas de forma simplificada para facilitar a compreensão, já aos alunos de graduação não foi omitida nem reduzida nenhuma das deduções. Os licenciandos apresentadores do minicurso seguiram rigorosamente o que constava no "Duas Novas Ciências" (GALILEI, 1988).

\section{Considerações finais}

O progresso da ciência está muito longe de ser linear e perfeito como, muitas vezes é apresentado na mídia, ensinado nas escolas e em muitos materiais didáticos. Mesmo na graduação em física a forma tradicional de ensinar ciências, excluindo o ensino sobre a Ciência, faz com que seja reforçada a concepção empirista, a-histórica, descontextualizada e infalível da ciência.

A abordagem historicamente contextualizada, a apreciação do momento histórico, a realização de experimentos históricos e sua análise, segundo os métodos de Galileu, puderam despertar nesses alunos a compreensão de que a ciência faz parte da cultura humana (ZANETTIC, 1989) e, tal como as artes e a política, a ciência é uma construção humana, cheia de erros e acertos, de altos e baixos.

A partir do estudo da vida e obra de Galileu, dos nuances, dilemas e contradições de sua obra e a apreciação de trechos de textos originais foi possível fortalecer a compreensão sobre os conceitos estudados e possibilitou discussões importantes e interessantes sobre a natureza da ciência.

Pudemos perceber, também, que a proposta de trabalhar HFC e NDC através da Pedagogia de Projetos, despertou maior interesse desses alunos nas discussões dos temas, estimulou-os a se aterem aos detalhes históricos estudados e 
gerou diversas discussões práticas importantes para estes licenciandos, em termos métodos didáticos apropriados para tal abordagem no Ensino Médio e Graduação.

Uma vez que eles tiveram como desafio a montagem e aplicação de um minicurso, os mesmos foram desafiados a pensar na melhor maneira de ensinar os temas de HFC e NDC, os melhores argumentos a serem usados, a sequência didática mais favorável, etc. Isso contribuiu em muito para a prática pedagógica destes licenciandos e forneceu subsídios para uma melhor avaliação sobre fontes de pesquisa em história da ciência e critérios para avaliar materiais didáticos para suas futuras práticas pedagógicas em HFC e NDC.

\section{Referências bibliográficas}

EL-HANI, C. N. Notas sobre o Ensino de História e Filosofia da Ciência na Educação Científica de Nível Superior. In: SILVA, C. C. (Org). Estudos de História e Filosofia das Ciências: subsídios para aplicação no ensino. São Paulo: Editora Livraria da Física, 2006. p. 3-21.

FERNÁNDEZ, I. Análisis de las concepciones docentes sobre la actividad científica: uma propuesta de transformación. 2000. Tesis (Doctotal) - Departament de Didàctica de les Ciencies Experimentals, Universidad de Valencia, Valencia.

FERRARI, M. John Dewey: o pensador que pôs a prática em foco. Nova Escola, São Paulo, jul. 2008. Edição especial grandes pensadores. Disponível em: $<$ http://revistaescola.abril.com.br/historia/pratica-pedagogica/john-dewey428136.shtml>. Acesso em: 20 nov. 2013.

FERRETTI, C. J.; ZIBAS, D. M. L.; TARTUCE, G. L. B. P. Protagonismo juvenil na literatura especializada e na reforma do ensino médio. Cadernos de Pesquisa, v. 34, n. 122, maio/ago. 2004.

FORATO, T. C. M. História e Natureza da Ciência no Ensino de Física: análise da preparação do professor. In: ENCONTRO DE PESQUISA EM ENSINO DE FÍSICA, XIII, 2011, Foz do Iguaçu.

FORATO, T. C. M.; MARTINS, R. de A.; PIETROCOLA, M. Prescrições historiográficas e saberes escolares: alguns desafios e riscos In: ENCONTRO NACIONAL DE PESQUISA EM ENSINO DE CIÊNCIAS, VII, 2009. Atas... Florianópolis. 
FREIRE Jr., O.; SERPA, L. F.; CARVALHO, M. P. A presença da história no ensino das ciências: um estudo comparativo entre o Brasil e Portugal (1960-1980). In: CONGRESSO LUSO-BRASILEIRO DE HISTÓRIA DA CIÊNCIA E DA TÉCNICA, 1, 2001, Évora e Aveiro. Atas... Évora: Universidade de Évora, 2000. v. 1. p. 720-734.

FREIRE, P. Pedagogia do Oprimido. Rio de Janeiro: Paz e Terra, 1987.

GALILEI, G. Duas Novas Ciências. São Paulo: Nova Stella. 1988.

GIL-PÉREZ, D.; MONTOSO, I. F.; ALÍS, J. C.; CACHAPUZ, A.; PRAIA, J. Para uma imagem não deformada do trabalho científico. Ciência \& Educação, v. 7, n. 2, p. 125-153, 2001.

HARRES, J. B. S. Uma revisão de pesquisas nas concepções de professores sobre a natureza da ciência e suas implicações para o ensino. Investigações em Ensino de Ciências, v. 4, n. 3, dez. 1999.

HERNÁNDEZ, F. Pesquisar para aprender: educador espanhol explica como trabalhar a aprendizagem utilizando projetos. Revista Nova Escola, n. 154, ago. 2002. Disponível em:

$<$ http://www.firb.br/editora/index.php/teste/article/download/33/40>. Acesso em: 03 mar. 2013.

HERNÁNDEZ, F.; VENTURA, M. A organização do currículo por projetos de trabalho. Tradução: Jussara Haubert Rodrigues. 5. ed. Porto Alegre: Artes Médicas, 1998.

HOLTON, G. What historians of science and science educators can do for one another? Science Education, v. 12, n. 7, p. 603-616, oct. 2003.

LEDERMAN, N. G. Students' and teachers' conceptions of the nature of science: a review of the research. Journal of Research in Science Teaching, New York, v. 29, n. 4, p. 331-359, 1992.

LEDERMAN, N. G. (Eds.) Handbook of research on Science Education. Mahwah, NJ: Lawrence Erlbaum Associates, 2007. p. 831-880.

MARTINS, A. F. P. História e Filosofia da Ciência no Ensino: há muitas pedras nesse caminho... Caderno Brasileiro de Ensino de Física, Florianópolis, v. 24, n. 1, p. 112-131, abr. 2007. 
MARTINS, A. F. P. História, filosofia, ensino de ciências e formação de professores: desafios, obstáculos e possibilidades. Educação: Teoria e Prática, v. 22, n. 40, mai/ago. 2012.

MARTINS, J. S. O trabalho com projetos de pesquisa: do ensino fundamental ao ensino médio. Campinas: Papirus, 2007.

Projetos de pesquisa: estratégias de ensino e aprendizagem em sala de aula. Campinas: Armazém do Ipê, 2005.

MARTINS, R. de A. O mito de Galileu desconstruído. Revista de História da Biblioteca Nacional, v. 5, Número Especial de História da Ciência 1, p. 24-27, 2010.

MATTHEWS, M. R. História, Filosofia e Ensino de Ciências: a tendência atual de reaproximação. Caderno Catarinense de Ensino de Física, v. 12, n. 3, p. 164214, dez. 1995.

MOREIRA, M. A.; MASSONI, N. T.; OSTERMANN, F. História e epistemologia da física na licenciatura em física: uma disciplina que busca mudar concepções dos alunos sobre a natureza da ciência. Revista Brasileira de Ensino de Física, v. 29, n. 1, p. 127-134, 2007.

NOGUEIRA, N. R. Pedagogia de Projetos: uma jornada interdisciplinar rumo ao desenvolvimento das múltiplas inteligências. São Paulo: Ética. 2002.

OLIVEIRA, B. J.; FREIRE Jr, O. Uma Conversa com Gerald Holton. Caderno Brasileiro de Ensino de Física, v. 23, n. 3, p. 315-328, dez. 2006.

PEDUZZI, L. O. Q.; PEDUZZI, S. S.; GRANDI. B. C. S.; HOFMANN, M. P. Caderno Catarinense de Ensino de Física: Uma Avaliação da sua Influência no Contexto Educacional. Caderno Catarinense de Ensino de Física, v. 7, n. 2, p. 85-119, ago. 1990.

PEDUZZI, L. O. Q. Sobre a utilização didática da história da ciência. In: PIETROCOLA, M. (Org.) Ensino de Física - conteúdo, metodologia e epistemologia numa concepção integradora. Florianópolis: Editora UFSC, 2001.

PEDUZZI, L. O. Q. As concepções espontâneas, a resolução de problemas e a história e filosofia da ciência em um curso de mecânica. 1998. 849f. Tese (Doutor em Ensino de Ciências Naturais) - UFSC, Florianópolis, 1998. 
PRADO, M. E. B. B. Pedagogia de projetos, 2003. Disponível em:

<http://www.eadconsultoria.com.br/matapoio/biblioteca/textos_pdf/texto18.pdf.> Acesso em: dez. 2013.

RUSSELL, C. Whigs and professional. Nature, n. 308, p. 777-8, 1984.

SAUERWEIN, I. P. S.; DELIZOICOV, D. Formação Continuada de Professores de Física do Ensino Médio: Concepções de Formadores. Caderno Brasileiro de Ensino de Física, v. 25, n. 3, p. 439-477, dez. 2008.

SAVIANI, D. Escola e democracia. 20. ed. São Paulo: Cortez Editora e Autores Associados, 1998.

VIEIRA, J. de A. Aprendizagem por Projetos na Educação Superior: Posições, Tendências e Possibilidades. Revista Travessias, 2010. Disponível em: $<$ http://www.unioeste.br/prppg/mestrados/letras/revistas/travessias/ed_004/artigos/ educacao/pdfs/APRENDIZAGEM\%20POR\%20PROJETOS.pdf>. Acesso em: 01 fev. 2014.

WHITAKER, M. A. B. History and quasi-history in physics education - part 1 . Physics Education, v. 14, p. 108-112, 1979.

ZANETIC, J. Física também é Cultura. 1989. Tese (Doutorado em Educação) Faculdade de Educação, Universidade de São Paulo, São Paulo.

ZYLBERSZTAJN, A. Galileu - um cientista e várias versões. Caderno Catarinense de Ensino de Física, v. 5, n. Especial, p. 36-48, 2009.

\section{Referências dos textos utilizados nas atividades de extensão}

ARAUJO, W. D. A Física do Impetus. In: A Gênese do Pensamento Galileano. Editora Livraria da Física, 2008.

ARAUJO, W. D. Abordagens teóricas em Filosofia e Histórica da Ciência. In: A Gênese do Pensamento Galileano. Editora Livraria da Física, 2008. p. 39-56.

ARAUJO, W. D. Galileu e o Experimento do Plano Inclinado. In: A Gênese do Pensamento Galileano. Editora Livraria da Física, 2008. p. 57-83.

BAPTISTA, J. P.; FERRACIOLI, L. A evolução do pensamento sobre o conceito de movimento. Revista Brasileira de Ensino de Física, v. 21, n. 1, 1999. 
COHEN, I. B. Caminhando para uma Física Inercial. In:

O Nascimento de uma Nova Física. cap. 5, 1967. p.12-27.

COHEN, I. B. Caminhando para uma Física Inercial. In:

O Nascimento de uma Nova Física. cap. 5, 1967. p. 88-134.

DRAKE, S. Free Fall and Uniform Acceleration. In: _. Galileo Studies: Personality, Tradition and Revolution. Ann Arbor: University of Michigan Press [1970], v. 1, 1970. p. 214-239.

GALILEI, G. Diálogo Sobre Duas Novas Ciências: Terceiro dia. In: HAWKING, Stephen (Ed.). Os gênios da ciência: sobre os ombros de gigantes. São Paulo: Elsevier, 2005. p. 214-230.

GALILEI, G. Diálogo Sobre Duas Novas Ciências: Terceiro dia. In: HAWKING, Stephen (Ed.). Os gênios da ciência: sobre os ombros de gigantes. São Paulo: Elsevier, 2005. p. 230-244.

Galileu Galilei: a Batalha pelo Céu. Disponível em:

$<$ https://www.youtube.com/watch?v=bufSXkgkCCo\&list=PL261533F8F3F5DD8 E>. Acesso em: 17 abr. 2013.

Galileu Galilei: o mensageiro das estrelas. Disponível em:

<https://www.youtube.com/watch?v=z11inivuIII>. Aceso em: 24 abr. 2013.

KOYRÉ, A. Galileu e Platão. In: ___ Estudos de História do Pensamento Científico. Rio de Janeiro: Ed. Forense universitária, 1991. p.165-p.196.

MARTINS, R. A. O mito de Galileu desconstruído. Revista de História da Biblioteca Nacional, v. 5, Número Especial de História da Ciência 1, p. 24-27, 2010.

PEDUZZI, L. O. Q. Física Aristotélica: por que não considerá-la no ensino da Mecânica? Caderno Catarinense de Ensino de Física, v. 13, n. 1, p. 48-63, abr. 1996.

PIRES, A. S. T. Galileu. In: Evolução das Ideais da Física. Livraria da Física: 2008. cap. 5, p.115- p.168.

ZYLBERSZTAJN, A. Galileu - um cientista e várias versões. Caderno Catarinense de Ensino de Física, v. 5, n. Especial, p. 36-48, 2009. 